\title{
Youth's Perspectives on a Sustainable Model for the Provision of Youth Friendly Sexual and Reproductive Health Services in Kenya: A Quantitative Approach
}

\author{
Mary W. Murigi*, Ramadimetja S. Mogale, Miriam M. Moagi \\ Faculty of Health Sciences, Department of Nursing Sciences, University of Pretoria, Hatfield, South Africa \\ Email: *mmurigi@kyu.ac.ke
}

How to cite this paper: Murigi, M.W., Mogale, R.S. and Moagi, M.W. (2020) Youth's Perspectives on a Sustainable Model for the Provision of Youth Friendly Sexual and Reproductive Health Services in Kenya: A Quantitative Approach. Journal of Biosciences and Medicines, 8, 100-115.

https://doi.org/10.4236/jbm.2020.88010

Received: June 30, 2020

Accepted: August 15, 2020

Published: August 18, 2020

Copyright $\odot 2020$ by author(s) and Scientific Research Publishing Inc. This work is licensed under the Creative Commons Attribution International License (CC BY 4.0).

http://creativecommons.org/licenses/by/4.0/

(c) (i) Open Access

\begin{abstract}
Nearly half of the world's population comprise youths. However, addressing their Sexual and Reproductive Health (SRH) remains a challenge. Globally countries are mandated to continually provide Youth Friendly Sexual and Reproductive Health services (YFSRHs) to the youth. The objective of this study was to assess and describe youth's perspectives on a sustainable model for the provision of YFSRHs in Kenya. Data was collected among 400 youths aged 18 - 24 years in Embu and Kirinyaga counties, Kenya. A structured questionnaire was utilized as the data collection tool. Collected data was analyzed using SAS statistical software version 9.4. Statistical threshold of $\mathrm{P} \leq$ 0.05 was used. Overall the mean age of the study participants was \pm standard deviation (SD) $21.2 \pm 1.86$ years. Majority of the participants' perspective on the health care system sustainability was that the waiting time at the facility should be less than an hour, accessible geographically (less than a kilometre), affordable ( $\leq 20 \mathrm{Ksh}$.), and convenient working hours (weekday and weekends ratio 1:1). Advocacy was on health care provider's attributes of politeness, welcoming, confidential and non-judgmental. The most preferred locations for the youth friendly centres by the participants were community and school based locations. Similarly, parental and community support was reported to highly contribute to sustained utilization and provision of the YFSRHs $(\mathrm{P}<$ 0.001). Unlike popular belief, $99.8 \%$ did not see the need for recreational facilities at the youth centres to ensure sustainability of the model. To ensure a sustainable model for the provision of YFSRHs, there is need for a multi-sectoral and stakeholder involvement that is; youth, health care system structure, health care service providers, parents and community. Further research is needed on parents and health care service provider's perspectives on
\end{abstract}


how to sustain the provision of YFSRH services.

\section{Keywords}

Youth's, Sexual and Reproductive Health, Youth Friendly Services, Sustainable Model

\section{Introduction}

The youth defined as those aged $15-24$ years [1], comprise over 1.8 billion of the world's population with $90 \%$ living in developing countries [1]. In Kenya a youth is defined as a person in the age bracket of 15 - 35 years [2].

Youth experience adolescence as a critical transitional period from childhood to adulthood where they begin to express and experiment their sexuality [3]. In addition, adolescence is a stage where at an individual level youth become more vulnerable to negative SRH problems such as having sex with multiple partners, substance abuse, having low knowledge on Sexually Transmitted Infection (STIs), lack negotiating skills for safe sex; and having poor health-seeking behavior [4]. Health facilities therefore, need to provide YFSRH services that are accessible, acceptable, equitable, available, appropriate to the youth sub population [5]; and provide the services within a welcoming environment so that youth are able to return for the services and refer their friends [6].

The International Conference for Population and Development (ICPD) 1994 put YFSRH services on the global agenda inspiring policies and programmes globally [7]. However, over twenty years later there are still gaps [8]. Youth are still paying the ultimate price of inequalities in terms of provision and access to SRH services and rights; the services to this population are either inaccessible, unaffordable or inadequate to meet their SRH needs [9].

Youth face challenges accessing SRH services that are friendly in Sub-Saharan Africa. The challenges are due to lack of political will and a socio-cultural environment that believes they should not have access to SRH services [9]. In Nigeria for example while youth admit availability of SRH services, many do not find them to be youth-friendly, as they face stigma and discrimination when trying to access the SRH services [10]. Uganda has the world's youngest population with over $78 \%$ of its population being below the age of 30 years. Yet, like many developing countries, it faces challenges in meeting its YSRH needs due to inadequate YFS [9].

In Kenya, the minimum conditions for youth friendly services provision include; safe and basic range of services; accessibility; affordability; privacy; confidentiality; provider competence; provider's attitude; quality and consistency of health services; reliability and sustainability of health services and an inbuilt monitoring and evaluation systems [11]. Youth SRH was recognized as a priority within the Kenya Essential Package of Health (KEPH) [11]. Within KEPH, Kenya committed itself to providing services that are specific to the youth through the 
establishment of YFSRH health services within the health facilities. However, evidence has shown access to YFSRH services to this subpopulation is difficult as the services available are not friendly and are mostly designed for the adult population [12].

Amid a HIV pandemic that disproportionately affects youth, this study had applied relevance as it sorts to determine youth's perspectives on how sustained provision of YFSRH can be achieved in Kenya. Identifying the patterns of SRH services provision to the youth by youth, and understanding the factors associated therein aided in gaining evidence that will support the development of a sustainable model at the health facility levels, County level and the Country at large.

\section{Materials and Methods}

\subsection{Study Setting}

This study was specifically carried out in two Counties in Kenya; Embu County and Kirinyaga County. Embu County borders Kirinyaga County to the South West [13]. Kirinyaga County by the year 2014 had a population of 72,278 youth aged 18 - 24 years [13]. Currently, the county referral hospital does not have a Youth Friendly Centre (YFC) and therefore SRH services are offered to the youth using the integrated approach. In the integrated approach, YFSRH services to the youth in the county are integrated with other health care services for the adult population [14].

Embu County on the other hand by the year 2014, had a population of 70,078 youth aged 18 - 24 years [14]. Currently, Embu county and referral hospital is among the few hospitals in Kenya that has a YFC and therefore SRH services are offered to the youth using a targeted approach. In a Targeted approach YFSRH services to the youth are designed and offered in a setting that meets only the needs of the young people [14].

These two study settings were of relevance to this study as they provided the researchers with an opportunity to compare the youth perspectives on YFSRHs sustainability among the youth who have experienced an integrated approach while receiving SRH services and those who have experienced a targeted approach receiving SRH services.

\subsection{Study Design}

A quantitative approach was used to collect data between May to July 2019. Quantitative data was collected among the youth with an aim of assessing and describing their perspectives on how YFSRHs can be provided in Kenya to ensure sustainability.

\subsection{Ethical Approvals}

Faculty of Health Sciences Research Ethics Committee at the University of Pretoria, Ref No 749\2018 and National Commission for Science and Technology 
(NACOSTI) Kenya, Ref No NACOSTI \P\19\15388\28696, Authorization and approvals also from County directors of Health and the County directors of Education from each county.

\subsection{Study Participants}

Quantitative data was collected from 400 consenting youth aged 18 - 24 years in the two counties who gave a written consent to participate in the study. The researchers utilized simple random sampling to achieve a sample size of 400 . Every sampled youth was included from the population that was accessible in the health centers, youth clubs and youth churches in the community. Proportionately, 200 youths represented Kirinyaga County while the other 200 represented Embu County.

Youths are key stakeholders in the development of a sustainable model for the provision of YFSRH services and hence the choice to assess their perspectives in this study as they add relevance in terms of knowledge and ability to contribute meaningful information towards sustained provision of YFSRH services.

\subsection{Data Collection Instrument}

The data collection instrument was a structured questionnaire developed and designed by the researchers in line with; the research aim and objectives, the Social Ecological Model (SEM) [15] and in consultation with an experienced statistician. Guided by the structure and levels of SEM (Individual, intrapersonal, community and organization levels) [15], the questionnaire consisted of three sections. The first section provided demographic data followed by two separate sections on health system sustainability and family/community support sustainability respectively.

The tool was pre tested in an area bordering the study area among participants with similar characteristics as the participants in the main study inorder to maintain internal validity. The researcher followed three specific strategies to conduct a valid and reliable pre-test assessment of the questionnaire: behavior coding and individual debriefing [16]. The pre-test study conducted showed a high level of internal consistency and reliability of the instrument with a Cronbach Alpha of 0.7. The feedback from the pretest informed further refinement and finalization of the study instrument.

\subsection{Data Collection Process}

Data was collected from a random sample of 400 youth aged 18 - 24 years from places where the youth mostly converged. The questionairre was administered on a drop and pick sequence. A written consent was obtained as an indicator of the participants willingness to take part in the study. To ensure confidentiality, the complete questionairre was kept in a lockable container that only the principal researcher had access to. To ensure anonymity, the participants were not required to disclose their personal information or identities on the questionnaire. This process was replicated in the two counties. 


\subsection{Data Analysis}

The collected data was grouped into the mentioned three different sections to facilitate the processing of the data namely; socio-demographic data, health care system sustainability; and family and community sustainability data. Data was then coded and captured onto a Microsoft Excel spreadsheet and fed into a computer program SAS statistical software version 9.4 for processing. Descriptive data analysis was used to express demographic variables in terms of means and standard deviation. To analyze and describe quantitative data in terms of frequencies and percentages, chi-square test $\left(\chi^{2}\right)$ for equal proportion technique was used [17]. The thresh hold for statistical significance was set at $\mathrm{P}<0.05$.

\section{Results}

\subsection{Socio-Demographic Characteristics of the Study Participants}

Table 1 outlines the sociodemographic characteristics of the study participants.

Table 1. Sociodemographic characteristics of the participants.

\begin{tabular}{|c|c|c|c|}
\hline Characteristic & Category & Number $(n=400)$ & $\%$ \\
\hline \multirow[t]{3}{*}{ Age (years) } & $18-19$ & 92 & 23.0 \\
\hline & $20-21$ & 120 & 30.0 \\
\hline & $22-24$ & 188 & 47.0 \\
\hline \multirow[t]{2}{*}{ Gender } & Female & 184 & 46.0 \\
\hline & Male & 216 & 54.0 \\
\hline \multirow[t]{3}{*}{ Marital Status } & Married & 27 & 6.8 \\
\hline & Separated & 12 & 3.0 \\
\hline & Single & 361 & 90.2 \\
\hline \multirow[t]{2}{*}{ In a relationship, If not married $(n=373)$} & Yes & 205 & 55.0 \\
\hline & No & 168 & 45.0 \\
\hline \multirow[t]{3}{*}{ Education } & Secondary & 79 & 19.8 \\
\hline & Tertiary & 311 & 77.8 \\
\hline & primary & 10 & 2.4 \\
\hline \multirow[t]{4}{*}{ Religion } & Christian & 363 & 90.8 \\
\hline & Muslim & 27 & 6.8 \\
\hline & Buddhist & 2 & 0.5 \\
\hline & Non practicing & 17 & 8.0 \\
\hline \multirow[t]{3}{*}{ Occupation } & At school & 287 & 71.8 \\
\hline & Employed & 62 & 15.5 \\
\hline & Unemployed & 51 & 12.8 \\
\hline \multirow[t]{4}{*}{ Area of Residence } & Peri-Urban & 98 & 24.5 \\
\hline & Rural & 124 & 31.0 \\
\hline & Urban & 176 & 44.0 \\
\hline & No response & 2 & 0.5 \\
\hline \multirow[t]{3}{*}{ Lives with parents } & No & 213 & 53.3 \\
\hline & Yes & 185 & 46.3 \\
\hline & No response & 2 & 0.4 \\
\hline
\end{tabular}


A total of 400 study participants enrolled from two study sites, namely Embu County and Kirinyaga County (ratio 1:1). In both counties, the age of the participants ranged from 18 to 24 years with the mean \pm standard deviation (SD) age being $21.2 \pm 1.86$ years. Majority of the participants were male (54.0\%), Christians $(90.8 \%)$ and scholars $(71.8 \%)$. At the time of the study, most of the participants (44.0\%) hailed form an urban area and were not living with family members (53.0\%).

\subsection{Health Care System Attributes for a Sustainable Model of YFSRH Care Services}

Table 2 illustrates youth perspective on how health care facilities could improve to ensure they keep utilizing YFSRH care services.

To ensure health care system sustainability, majority of the participants reported: convenient time would be on weekdays and weekends on a fifty fifty proportion. Waiting time at the YFSRH care clinic should be less than one hour (71.5\%); health facilities offering YFSRH care services should be within a distance of less than $1 \mathrm{~km}$ from the area of residence (74.0\%) and a friendly service fee less than Ksh. 20 (42.3\%). Noteworthy is only a minority $(6.0 \%)$ proposed free YFSRH care services.

In other health care system attributes, participants considered Health Service Providers (HSPs) being non-judgmental (72.0\%), polite (71.3\%), welcoming

Table 2. How health care facilities could improve to ensure that the youth keep seeking YFSRH care services.

\begin{tabular}{|c|c|c|c|}
\hline Attribute & Category & Number $(n=400)$ & $\%$ \\
\hline \multirow{4}{*}{ Convenient working hours/days } & Weekdays & 192 & 48.0 \\
\hline & Weekends & 185 & 46.2 \\
\hline & Full time & 20 & 5.0 \\
\hline & No response & 3 & 0.8 \\
\hline \multirow{4}{*}{ Waiting time } & $<1$ hour & 286 & 71.5 \\
\hline & 1 hour & 73 & 18.2 \\
\hline & $>1$ hour & 37 & 9.3 \\
\hline & No response & 4 & 1.0 \\
\hline \multirow{3}{*}{ Health facility be within distance } & $<1 \mathrm{Km}$ & 295 & 74.0 \\
\hline & $1 \mathrm{Km}$ & 73 & 18.3 \\
\hline & $>1 \mathrm{Km}$ & 29 & 7.3 \\
\hline \multirow{6}{*}{ Friendly cost of health services (Ksh.) } & No response & 2 & 0.5 \\
\hline & $<20$ & 169 & 42.3 \\
\hline & 20 & 135 & 33.3 \\
\hline & $>20$ & 67 & 17.0 \\
\hline & Free & 24 & 6.0 \\
\hline & No response & 5 & 1.3 \\
\hline
\end{tabular}


(65.7\%), and confidential (61.3\%) as significant attributes in sustaining the provision and utilization of YFSRH care services.

Table 3 shows youths preferred SRH services at the health care facilities to enhance sustaibability of the YFSRH services.

Most of the study participants advocated for availability of a wide range of SRH servcies, key to note however is that $99.8 \%$ of the study participants did not feel the need to have sports/recreational activities inorder to enhance sustained provision of the YFSRH services.

Table 3. Preffered SRH services at the health care facilities to enhance sustaibability of the YFSRH services.

\begin{tabular}{|c|c|c|c|}
\hline Proposed YFSRH care service & Response & Number $(n=400)$ & $\%$ \\
\hline \multirow{2}{*}{ Family planning services (Contraceptives, condoms) } & No & 91 & 22.8 \\
\hline & Yes & 309 & 77.3 \\
\hline \multirow{3}{*}{ Abortion services } & No & 267 & 66.8 \\
\hline & Yes & 132 & 33.0 \\
\hline & No response & 1 & 0.3 \\
\hline \multirow{3}{*}{ Post abortion care services } & No & 298 & 74.5 \\
\hline & Yes & 101 & 25.3 \\
\hline & No response & 1 & 0.3 \\
\hline \multirow{3}{*}{ Voluntary Counseling and Testing (VCT) } & Yes & 267 & 66.8 \\
\hline & No & 132 & 33.0 \\
\hline & No response & 1 & 0.3 \\
\hline \multirow{3}{*}{ Treatment of all diseases } & Yes & 252 & 63.0 \\
\hline & No & 147 & 36.8 \\
\hline & No response & 1 & 0.3 \\
\hline \multirow{2}{*}{ Cancer screening } & Yes & 279 & 69.8 \\
\hline & No & 120 & 30.0 \\
\hline \multirow{4}{*}{ Treatment of sexually transmitted Infections/diseases } & No response & 1 & 0.3 \\
\hline & Yes & 222 & 55.5 \\
\hline & No & 177 & 44.4 \\
\hline & No response & 1 & 0.3 \\
\hline \multirow{3}{*}{ Care of pregnant young women } & Yes & 218 & 54.5 \\
\hline & No & 181 & 45.3 \\
\hline & No response & 1 & 0.3 \\
\hline \multirow{3}{*}{$\begin{array}{l}\text { General health information, education and counseling } \\
\text { (e.g. on menstruation, wet dreams, conception, etc.) }\end{array}$} & No & 167 & 41.8 \\
\hline & Yes & 232 & 58.0 \\
\hline & No response & 1 & 0.3 \\
\hline \multirow{2}{*}{ Sports and recreational activities } & No & 399 & 99.8 \\
\hline & No response & 1 & 0.3 \\
\hline
\end{tabular}


The most preferred place for setting up YFSRH service centres was within the community (53\%) while school going youth preferred school based (46\%).

\subsection{Family and Community Support Attributes for a Sustainable Model of YFSRH Care Services}

Table 4 depicts youths perception on how family and the community could contribute to the sustainability of YFSRH care services provision.

The parental support most preferred by the study participants inorder to have sustained utilization of YFSRH care services by the youth was: discussing on SRH with the youths (68.3\%), encouraging the youth to visit the health facilities for reproductive health services (67.0\%), giving advice and lessons on sexual health and sex matters to the youth (68.5\%), avoiding discrimination and stigmatization

Table 4. Family and community contribution to the sustainability of YFSRH care services provision.

\begin{tabular}{|c|c|c|c|}
\hline Sustainability approaches & Response Category & Number $(n=400)$ & $\%$ \\
\hline \multirow[t]{3}{*}{$\begin{array}{l}\text { Provide money fare to the hospital and for } \\
\text { hospital fee }\end{array}$} & No & 180 & 45.0 \\
\hline & Yes & 219 & 54.8 \\
\hline & No response & 1 & 0.3 \\
\hline \multirow[t]{3}{*}{$\begin{array}{l}\text { Hold discussions with the youth on sexual } \\
\text { health and sex matters }\end{array}$} & No & 126 & 31.5 \\
\hline & Yes & 273 & 68.3 \\
\hline & No response & 1 & 0.3 \\
\hline \multirow[t]{3}{*}{$\begin{array}{l}\text { Give advice and lessons on sexual health and } \\
\text { sex matters }\end{array}$} & No & 125 & 31.3 \\
\hline & Yes & 274 & 68.5 \\
\hline & No response & 1 & 0.3 \\
\hline \multirow[t]{3}{*}{ Be less judgmental } & No & 156 & 39.0 \\
\hline & Yes & 243 & 60.8 \\
\hline & No response & 1 & 0.3 \\
\hline \multirow[t]{3}{*}{ Avoid discrimination/stigmatization } & No & 142 & 35.5 \\
\hline & Yes & 257 & 64.3 \\
\hline & No response & 1 & 0.3 \\
\hline \multirow[t]{3}{*}{$\begin{array}{l}\text { Encourage the youth to attend the health } \\
\text { facilities for reproductive health services }\end{array}$} & No & 131 & 32.8 \\
\hline & Yes & 268 & 67.0 \\
\hline & No response & 1 & 0.3 \\
\hline \multirow[t]{3}{*}{$\begin{array}{l}\text { Accompany the youth to the health facility } \\
\text { when need be }\end{array}$} & No & 270 & 67.5 \\
\hline & Yes & 129 & 32.3 \\
\hline & No response & 1 & 0.3 \\
\hline
\end{tabular}


(64.3\%), parents being less judgmental (60.8\%), and provision of the requisite financial support for seeking the services (54.8\%). Majority (67.5\%) however, opposed parents accompanying the youth to the health facility when need be.

\subsection{Evaluation of the Association between Sociodemographic Characteristic and Health Care System Sustainability Attributes}

\subsubsection{Convenient Facility Working Hours}

Table 5 shows the variation of the responses to the inquiry on convenient facility working hours by sociodemographic attributes of the participants.

The interaction between convenient facility working hours with demographics showed significance with $\mathrm{p}=0.02$ for age; $\mathrm{p}=0.01$ for marital status, in a relationship, occupation and county; and $\mathrm{p}=0.05$ for education level. More than $50 \%$ of participants from Embu and Kirinyaga counties indicated that their suitable facility working hours are weekdays and weekends, respectively. Only a few percentages $(\leq 10)$ of participants across all levels of sociodemographic indicated that they would prefer the convenient working hours for the centers to be fulltime.

\subsubsection{Distance and Waiting Time and at the Health Facility}

Irrespective of their social demographics, all the participants preferred the distance

Table 5. Variation of the responses to the inquiry on convenient facility working hours by sociodemographic attributes of the participants.

\begin{tabular}{|c|c|c|c|c|c|}
\hline \multirow[t]{2}{*}{ Variables } & \multicolumn{3}{|c|}{ Time of operation (\%) } & \multirow[t]{2}{*}{$x^{2}$ value } & \multirow[t]{2}{*}{ P-value } \\
\hline & Full time & Weekdays & Weekends & & \\
\hline $18-19$ yrs & 3 & 39 & 58 & & \\
\hline $20-21 \mathrm{yrs}$ & 9 & 46 & 45 & 11.78 & 0.02 \\
\hline $22-24$ yrs & 3 & 54 & 43 & & \\
\hline Married & 0 & 74 & 26 & & \\
\hline Separated & 0 & 75 & 25 & 12.61 & 0.01 \\
\hline Single & 6 & 45 & 49 & & \\
\hline single $\&$ in relationship & 4 & 48 & 48 & & \\
\hline single not in relationship & 7 & 42 & 51 & 16.64 & 0.01 \\
\hline Not applicable & 0 & 74 & 26 & & \\
\hline Primary & 0 & 90 & 10 & & \\
\hline Secondary & 6 & 53 & 41 & 9.53 & 0.05 \\
\hline Tertiary & 5 & 45 & 50 & & \\
\hline At school & 5 & 43 & 52 & & \\
\hline Employed & 2 & 63 & 35 & 14.11 & 0.01 \\
\hline Unemployed & 10 & 57 & 33 & & \\
\hline Embu & 5 & 56 & 39 & & \\
\hline Kirinyaga & 6 & 40 & 54 & 10.32 & 0.01 \\
\hline
\end{tabular}


to the health facility to be less than 1 kilometer, similarly, all the participants preferred waiting time of less than an hour at the health facility.

\subsubsection{Cost of Services at the Health Facility}

Health facility costs interaction with marital status $\left(\mathrm{p}=0.0002, X^{2}=25.92\right)$, having relationship $\left(\mathrm{p}=0.00118, X^{2}=16.40\right)$, level of education $\left(\mathrm{p}=0.0002, X^{2}\right.$ $=26.68)$ employment status $\left(\mathrm{p}=0.0021, X^{2}=20.72\right)$ and county $\left(\mathrm{p}=0.0200, X^{2}\right.$ $=9.84)$ was significant at $\mathrm{P} \leq 0.05$. Across majority of the sociodemographic, the study participants preferred health facility cost of $\leq 20$ Kenyan shillings (Ksh).

\subsubsection{Health care Service Provider Characteristics}

Figure 1 illustrates the health care service provider attributes preferred by the youth from the two study regions in Kenya.

Analysis of the desirability of the various attributes of a health service provider by socio-demographic attributes of the participants depicted preference of a healthcare provider who maintained confidentiality $\mathrm{p}=0.05$, welcoming $\mathrm{p}=$ 0.003 , polite $p=0.004$ and non-judgmental $p=0.003$. Key to note is that the participants from the different study regions preferred different attributes.

\subsection{Family and Community Support to Enhance Sustainable Provision and Utilization of YFSRH Care Services}

Table 6 shows statistical analysis of youth's perspectives on ways in which the family members and the community could be involved in ensuring a YFSRH services model sustainability.

The study explored youths' perspectives on ways in which the family members and the community could be involved in ensuring continued utilization and provision of the YFSRH care services in the health facilities, the findings exhibited a significantly higher proportion of agreement $\mathrm{P}<0.001$.

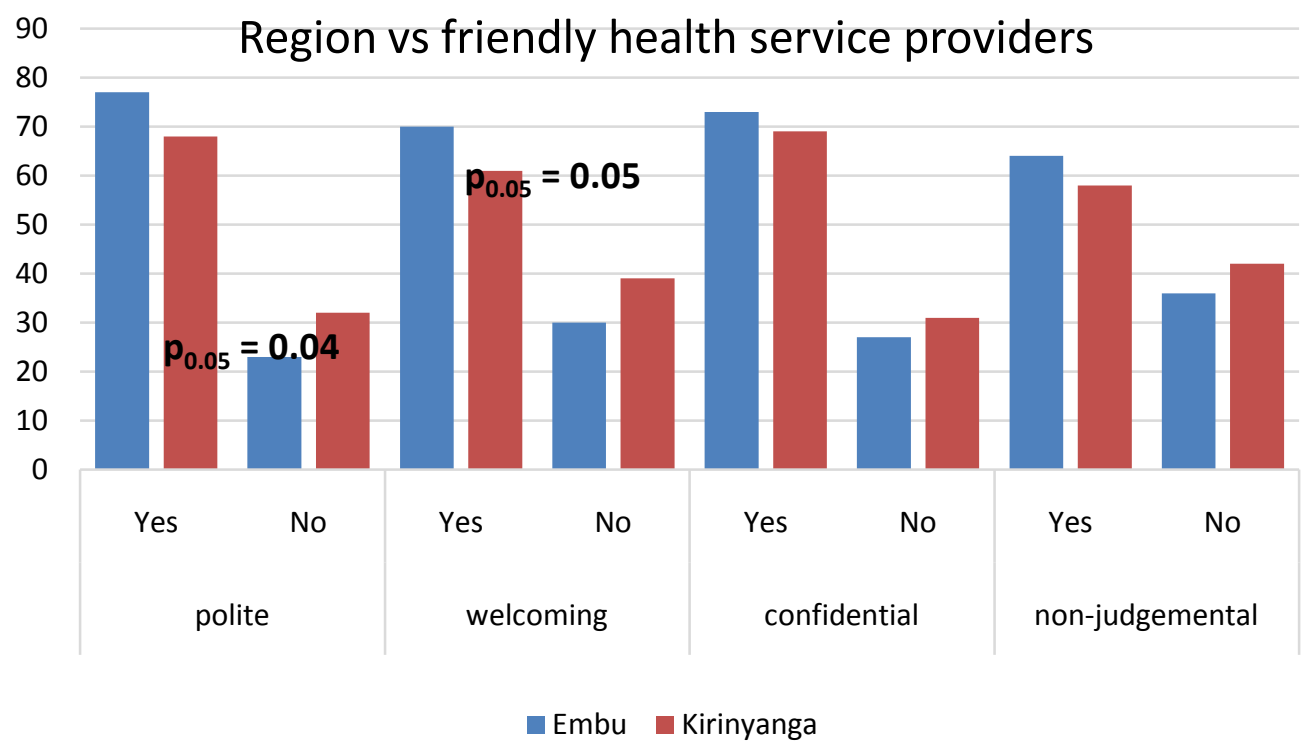

Figure 1. Region vs health service provider attributes. 
Table 6. Ways in which the community can be involved in ensuring you continue using the YFSRH care services in the health facilities.

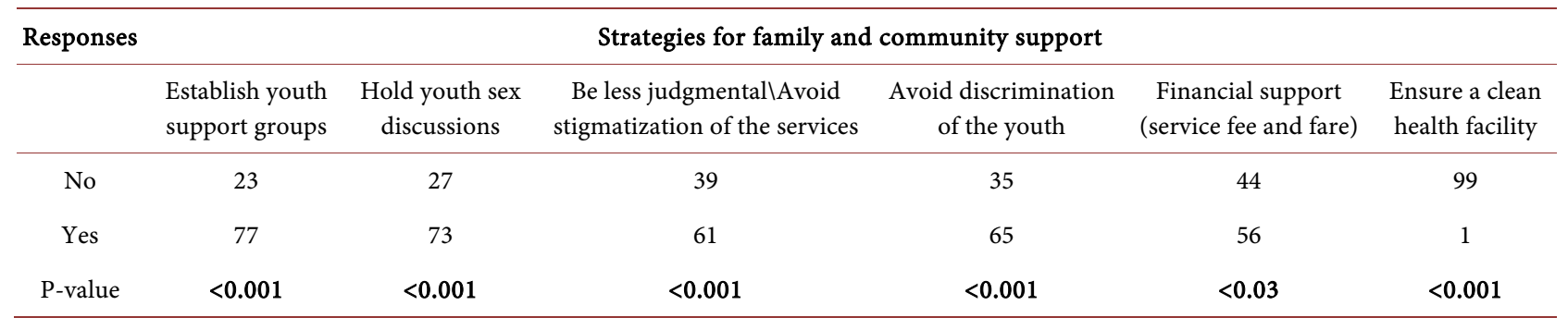

\section{Discussion}

This study sort to assess and describe youth's perspectives on a sustainable model for the provision of YFSRHs. Two key areas of action to enhance sustained provision and utilization of YFSRHs emerged: One the health care system improvement including; characteristics related to the service providers, the health facility itself, and the program design and Two parental support and community involvement.

The findings from this study show the health facilities need to: be accessible geographically (less distance) and financially (less fare to the facility), have convenient opening time and less waiting time; and have a friendly and affordable service fee in order to ensure sustainability of the SRH services. These findings are in agreement with those reported in a study conducted in Kenya which reported that for YFSRH services to be acceptable to this sub-population, they should be offered at the right time, in the right place, at the right fee and in the right manner [12]. In yet another study conducted in Kenya, user fee charged at the health facilities hindered the young people from utilizing youth friendly services [18]. Similarly, in Zimbabwe youths did not utilize SRH services because the distance was too far [19].

While poverty is a factor that is fueling the practice of unsafe or unprotected sexual activities in SSA through transactional sexual activities [20], the cost of seeking health care on the other hand for youth include not only paying for SRH services and the travelling expenses but also loss of school time for those who are pupils/students [21]. Cost poses a large barrier to sexual and reproductive health services utilization for this sub population, who are usually financially dependent on their parents, or in the case of married adolescent girls, their husbands. The most preferred location in terms of the programme design from the study was within the community and in the schools. The community and school based approaches as advocated for by the youth could be necessitated by the need for convenience in terms of accessibility as most youths in the age bracket of 18-24 years spend most of their time in schools or within the community as they may not need the bus fare. The national guidelines in Kenya recommend three models of youth-friendly service provision, each with an essential service package: Youth Centre Based Model; Clinic Based Model and School Based Model [22]. What should be experimented therefore is decentralization of the clinic based 
model to a community and a school based model. The findings of this study concurs with a study in Ghana which reported that school-based and peer outreach intervention activities increased young people's usage of the SRH services more than training HSPs on youth friendly services [23].

The finding of these study also largely indicated service provider attributes as key to sustainability of the YFSRH services. The HSP attributes included: being non-judgmental, polite, welcoming, and maintaining confidentiality. These findings are substantiated by a study in sub-Saharan Africa that reported, negative HSPs attitude, poor knowledge and skills of youth SRH services and lack of essential drugs and equipment as the factors associated with inadequate provision of the YFSRH services [24]. Three separate studies conducted in South Africa also confirmed the findings where lack of confidentiality, lack of privacy, having to show soiled sanitary products to obtain contraceptives lack of youth-friendly training among staff; and healthcare workers expressing negative opinions about young people seeking SRH information, were hindrances to continued use of the YFSRH services [25] [26] [27]. In yet another study in Tanzania HSPs paternalistic attitude, lack of knowledge on young people's sexual and reproductive health, poor signage and reception, lack of confidentiality and privacy were cited as barriers to sustained utilization and provision of the YFSRH services [28].

Parental support and community involvement often would lead to sustained provision and utilization of the SRH services. Youth felt parents and the community should be involved in financial support, Information, Education and Communication (IEC) with the youth on SRH issues, being less judgmental and de-stigmatization of the youth friendly services. According to the youth's perspectives, these would in turn decrease discrimination of the youth seeking the YFSRH services. Two separate studies in Ethiopia reported low utilization of YFSRH services however, youths who had parental discussion on SRH issues more likely to continually utilize the services [20] [29]. Youths who lived with their mothers were more likely to utilize the services than those living with their fathers since mothers are easier to talk to [29]. Community members approve SRH services to young people which they feel are educative and preventive in nature and disapprove services which they feel encourage young people to engage in sexual activity [21] [29] [30].

Teachers and parents are unwilling to discuss sexual health with the young people, believing that they don't need such information or that doing so will encourage them to become sexually active [31]. However, evidence has shown that interventions that ask parents to communicate with their children about SRH issues are effective in improving knowledge and their sexual intentions [31]. Parents are however misinformed and need support to first improve their own familiarity with the SRH topics and become comfortable opening an SRH conversation with their children. Parents' wealth, education, religion, and attitudes toward gender roles, as well as their own sexual/relationship experiences, influence their expectations for their children [1]. 
The study shows minimal support for recreational facilities in the youth centers as an approach to enhance sustainability. Instead, of importance to the youth is availability of the SRH services and collaborative support from all the stakeholders. There is need to conduct a large scale comparative study that targets to examine youths' preferences between a targeted approach and an integrated approach to accessing YFSRH services.

\section{Conclusion}

Results from the study showed the importance of incorporating the youth in the decision making of their YFSRH needs and services. Their Voices need to be heard and are key for sustainable implementation of their programmes. In addition, the results of the study showed that in the viewpoints of the youth, for a sustainable model for the provision of YFSRH services in Kenya, hospitals need to ensure geographical accessibility, affordability, availability, and appropriateness of the services. Secondly, health service providers need to be polite, confidential, nonjudgmental and welcoming to the youths seeking the services. Additionally, community and parental support including; being less judgmental, avoiding stigmatization of the services, holding youth sexual health discussions, providing financial support (services fee and fare) and establishing youth support groups are needed. Unlike popular belief and focus of majority of the implemented youth centers where focus is on the recreational activities, this study depicted that priority to the youths is not the recreational facilities but rather fully equipped youth centers and available YFSRH services. The youth are the backbone of any country; therefore, paying attention to their sexual and reproductive health is a life-time investment that is likely to have positive effects on behavior and lifestyle during the entire course of the youth's life. There is need for implementation of YFSRH services that wholly cater and accommodate the opinion of youth as the service users.

\section{Recommendations}

The process of developing a sustainable model for the provision of YFSR services should be all inclusive and allow participation of youth themselves. This would enhance youths' understanding on the SRH issues and the SRH rights and encourage ownership. Further research is needed on parents and health care service provider's perspectives on how to sustain the provision of YFSRH services in Kenya. Similarly, a future large scale study is needed involving all the stake holders in other regions in Kenya on how a sustainable model for the provision of YFSRH services in Kenya can be developed.

\section{Acknowledgements}

The authors would like to sincerely thank the department of Nursing, University of Pretoria for support during the entire review process. Special thanks to Cynthia Ngwane, the Statician recommended by the University of Pretoria for the 
immense assistance in data analysis.

\section{Conflicts of Interest}

The authors declare that they have no conflicts of interest regarding the publication of this paper.

\section{References}

[1] UNFPA (2014) ICPD beyond 2014 Issue Brief: Investing in the Capabilities of Adolescents and Youth. UNFPA.

[2] MOYA (2006) Kenya National Youth Policy 2006. Ministry of Youth Affairs, Nairobi.

[3] UN (2012) World Population Monitoring Adolescents and Youth; a Concise Report. United Nations, New York.

[4] Murigi, M.D., et al. (2016) Overcoming Barriers to Contraceptive Uptake among Adolescents: The Case of Kiambu County, Kenya. Journal of Biosciences and Medicines, 4, 1-10. https://doi.org/10.4236/jbm.2016.49001

[5] WHO (2012) Making Health Services Adolescent Friendly: Developing National Quality Standards for Adolescent Friendly Health Services.

[6] Godia, P.M., Olenja, J.M., Hoffman, J.J. and Van Den Broek, N. (2014) Young People's Perception of Sexual and Reproductive Health Services in Kenya. BMC Health Services Research, 14, Article No. 172. https://doi.org/10.1186/1472-6963-14-172

[7] Sippel, S. (2014) ICPD beyond 2014: Moving beyond Missed Opportunities and Compromises in the Fulfillment of Sexual and Reproductive Health and Rights. Global Public Health, 9, 620-630. https://doi.org/10.1080/17441692.2014.921828

[8] Chandra-Mouli, V., Svanemyr, J., Amin, A., Fogstad, H., Say, L., Girard, F., et al. (2015) Twenty Years after International Conference on Population and Development: Where Are We with Adolescent Sexual and Reproductive Health and Rights? Journal of Adolescent Health, 56, S1-S6. https://doi.org/10.1016/j.jadohealth.2014.09.015

[9] Renzaho, A.M., Kamara, J.K., Georgeou, N., et al. (2017) Sexual, Reproductive Health Needs, and Rights of Young People in Slum Areas of Kampala, Uganda: A Cross Sectional Study. PLoS ONE, 12, e0169721. https://doi.org/10.1371/journal.pone.0169721

[10] Bello, B.M., Fatusi, A.O., Adepoju, O.E., Maina, B.W., Kabiru, C.W., Sommer, M., et al. (2017) Adolescent and Parental Reactions to Puberty in Nigeria and Kenya: A Cross-Cultural and Intergenerational Comparison. The Journal of Adolescent Health, 61, S35-S41. https://doi.org/10.1016/j.jadohealth.2017.03.014

[11] MOH (2005) National Guidelines for Provision of Adolescent Youth-Friendly Services (YFS) in Kenya. Ministry of Health, Division of Reproductive Health, Nairobi.

[12] Godia, P.M., Olenja, J.M., Lavussa, J.A., et al. (2013) Sexual Reproductive Health Service Provision to Young People in Kenya: Health Service Providers' Experiences. BMC Health Services Research, 13, Article No. 476.

[13] KNBS (2015) County Statistical Abstract EMBU County. Kenya National Bureau of Statistics (KNBS), Nairobi.

[14] KNBS (2015) County Statistical Abstract KIRINYAGA County. Kenya National Bureau of Statistics (KNBS), Nairobi. 
[15] Stokols, D. (1996) Translating Social Ecological Theory into Guidelines for Community Health Promotion. American Journal of Health Promotion, 10, 282-298. https://doi.org/10.4278/0890-1171-10.4.282

[16] Bolarinwa, O.A. (2015) Principles and Methods of Validity and Reliability Testing of Questionnaires Used in Social and Health Science Researches. Nigerian Postgraduate Medical Journal, 22, 195. https://doi.org/10.4103/1117-1936.173959

[17] Holt, D., Scott, A.J. and Ewings, P.D. (1980) Chi-Squared Tests with Survey Data. Journal of the Royal Statistical Society. Series A (General), 143, 303-320. https://doi.org/10.2307/2982131

[18] Onyando, J.O. and Njuguna, S. (2018) Factors Influencing Effectiveness of Youth Friendly Centres in Kenya: A Case of Kisumu County.

[19] Sommer, M. and Mmari, K. (2015) Addressing Structural and Environmental Factors for Adolescent Sexual and Reproductive Health in Low- and Middle-Income Countries. American Journal of Public Health, 105, 1973-1981. https://doi.org/10.2105/AJPH.2015.302740

[20] Ayehu, A., Kassaw, T. and Hailu, G. (2016) Level of Young People Sexual and Reproductive Health Service Utilization and Its Associated Factors among Young People in Awabel District, Northwest Ethiopia. PLOS ONE, 11, e0151613. https://doi.org/10.1371/journal.pone.0151613

[21] Binu, W., Marama, T., Gerbaba, M. and Sinaga, M. (2018) Sexual and Reproductive Health Services Utilization and Associated Factors among Secondary School Students in Nekemte Town, Ethiopia. Reproductive Health, 15, 64. https://doi.org/10.1186/s12978-018-0501-Z

[22] MOH (2015) National Adolescent Sexual and Reproductive Health Policy. Nairobi.

[23] Aninanya, G.A., Debpuur, C.Y., Awine, T., Williams, J.E., Hodgson, A. and Howard, N. (2015) Effects of an Adolescent Sexual and Reproductive Health Intervention on Health Service Usage by Young People in Northern Ghana: A Community-Randomised Trial. PLoS ONE, 10, e0125267. https://doi.org/10.1371/journal.pone.0125267

[24] Jonas, K., Crutzen, R., Van Den Borne, B. and Reddy, P. (2017) Healthcare Workers' Behaviours and Personal Determinants Associated with Providing Adequate Sexual and Reproductive Healthcare Services in Sub-Saharan Africa: A Systematic Review. BMC Pregnancy and Childbirth, 17, Article No. 86. https://doi.org/10.1186/s12884-017-1268-x

[25] Geary, R.S., Gómez-Olivé, F.X., Kahn, K., Tollman, S. and Norris, S.A. (2014) Barriers to and Facilitators of the Provision of a Youth-Friendly Health Services Programme in Rural South Africa. BMC Health Services Research, 14, Article No. 259. https://doi.org/10.1186/1472-6963-14-259

[26] Geary, R.S., Webb, E.L., Clarke, L. and Norris, S.A. (2015) Evaluating Youth-Friendly Health Services: Young People's Perspectives from a Simulated Client Study in Urban South Africa. Global Health Action, 8, 26080. https://doi.org/10.3402/gha.v8.26080

[27] Moult, K. and Müller, A. (2016) Navigating Conflicting Laws in Sexual and Reproductive Health Service Provision for Teenagers. Curationis, 39, 1-7. https://doi.org/10.4102/curationis.v39i1.1565

[28] Mchome, Z., Richards, E., Nnko, S., Dusabe, J., Mapella, E. and Obasi, A. (2015) A "Mystery Client" Evaluation of Adolescent Sexual and Reproductive Health Services in Health Facilities from Two Regions in Tanzania. PLoS ONE, 10, e0120822. https://doi.org/10.1371/journal.pone.0120822 
[29] Birhanu, Z., Tushune, K. and Jebena, M.G. (2018) Sexual and Reproductive Health Services Use, Perceptions, and Barriers among Young People in Southwest Oromia, Ethiopia. Ethiopian Journal of Health Sciences, 28, 37-48.

https://doi.org/10.4314/ejhs.v28i1.6

[30] Tamang, L., Raynes-Greenow, C., McGeechan, K. and Black, K.I. (2017) Knowledge, Experience, and Utilisation of Sexual and Reproductive Health Services amongst Nepalese Youth Living in the Kathmandu Valley. Sexual \& Reproductive Healthcare, 11, 25-30. https://doi.org/10.1016/j.srhc.2016.09.002

[31] Chandra-Mouli, V., Chatterjee, S. and Bose, K. (2015) Do Efforts to Standardize, Assess and Improve the Quality of Health Service Provision to Adolescents by Government-Run Health Services in Low and Middle Income Countries, Lead to Improvements in Service-Quality and Service-Utilization by Adolescents? Reproductive Health, 13, 10. https://doi.org/10.1186/s12978-015-0111-y

\section{List of Abbreviations}

YFSRHs: Youth Friendly Sexual and Reproductive Health services

SRH: Sexual and Reproductive Health

STIs: Sexually Transmitted Infections

ICPD: International Conference for Population and Development

Ksh.: Kenyan shillings 